\title{
Antagonistic effect of TNF-alpha and insulin on uncoupling protein 2 (UCP-2) expression and vascular damage
}

\author{
Almudena Gómez-Hernández ${ }^{1,2,3^{*}}$, Liliana Perdomo ${ }^{1,2}$, Natalia de las Heras ${ }^{4}$, Nuria Beneit ${ }^{1,2}$, Óscar Escribano ${ }^{1,2}$, \\ Yolanda F Otero ${ }^{1,2}$, Carlos Guillén ${ }^{1,2}$, Sabela Díaz-Castroverde ${ }^{1,2}$, Beatriz Gozalbo-López ${ }^{1,2}$, Victoria Cachofeiro ${ }^{4}$, \\ Vicente Lahera ${ }^{4}$ and Manuel Benito ${ }^{1,2}$
}

\begin{abstract}
Background: It has been reported that increased expression of UCP-2 in the vasculature may prevent the development of atherosclerosis in patients with increased production of reactive oxygen species, as in the diabetes, obesity or hypertension. Thus, a greater understanding in the modulation of UCP-2 could improve the atherosclerotic process. However, the effect of TNF-a or insulin modulating UCP-2 in the vascular wall is completely unknown. In this context, we propose to study new molecular mechanisms that help to explain whether the moderate hyperinsulinemia or lowering TNF-a levels might have a protective role against vascular damage mediated by UCP-2 expression levels.

Methods: We analyzed the effect of insulin or oleic acid in presence or not of TNF-a on UCP-2 expression in murine endothelial and vascular smooth muscle cells. At this step, we wondered if some mechanisms studied in vitro could be of any relevance in vivo. We used the following experimental models: ApoE ${ }^{-/-}$mice under Western type diet for 2 , 6,12 or 18 weeks, BATIRKO mice under high-fat diet for 16 weeks and 52-week-old BATIRKO mice with o without anti-TNF-a antibody pre-treatment.

Results: Firstly, we found that TNF-a pre-treatment reduced UCP-2 expression induced by insulin in vascular cells. Secondly, we observed a progressive reduction of UCP-2 levels together with an increase of lipid depots and lesion area in aorta from ApoE ${ }^{-/-}$mice. In vivo, we also observed that moderate hyperinsulinemic obese BATIRKO mice have lower TNF- $a$ and ROS levels and increased UCP-2 expression levels within the aorta, lower lipid accumulation, vascular dysfunction and macrovascular damage. We also observed that the anti-TNF-a antibody pre-treatment impaired the loss of UCP-2 expression within the aorta and relieved vascular damage observed in 52-week-old BATIRKO mice. Finally, we observed that the pretreatment with iNOS inhibitor prevented UCP-2 reduction induced by TNF-a in vascular cells. Moreover, iNOS levels are augmented in aorta from mice with lower UCP-2 levels and higher TNF-a levels.
\end{abstract}

Conclusions: Our data suggest that moderate hyperinsulinemia in response to insulin resistance or lowering of TNF-a levels within the aorta attenuates vascular damage, this protective effect being mediated by UCP-2 expression levels through iNOS.

Keywords: TNF-a, Insulin, UCP-2, Atherogenesis

\footnotetext{
* Correspondence: algomezh@ucm.es

'Biochemistry and Molecular Biology Department, School of Pharmacy, Complutense University of Madrid, Madrid, Spain

${ }^{2}$ CIBER of Diabetes and Associated Metabolic Diseases, Madrid, Spain

Full list of author information is available at the end of the article
} 


\section{Background}

Uncoupling proteins (UCPs) belong to the family of mitochondrial transporter proteins and are important for lowering mitochondrial membrane potential and dissipating metabolic energy as heat, maintenance of respiration, glucose disposal rate, insulin secretion, prevention of reactive oxygen species (ROS) production [1,2]. UCP-1 was the first member identified, expressed primarily in brown adipose tissue and the major contributor to energy expenditure [3]. Other four members of UCP ( -2 to -5$)$ family have been indentified. In contrast to UCP- 4 and -5 , human UCP- 2 and -3 are both more closely related to UCP-1 [4,5]. UCP-2 is expressed widely and in human is highly expressed in white adipose tissue. Other tissues as skeletal muscle, heart, cell of immune system and vascular cells express considerable amounts of UCP-2 [6]. Recent studies from UCP-2 and -3 knockout mice suggest that both UCPs have uncoupling activity and decreased ROS production in macrophages and skeletal muscle, respectively [7-9]. More recently, a direct role for UCP-2 in the regulation of atherogenesis has been suggested by the observation that bone marrow transplantation from UCP-2-deficient mice to $\mathrm{LDLR}^{-/-}$mice markedly increased atherosclerotic lesion size [10]. Moreover, it has been described that UCP-2 overexpression in the vasculature may prevent the development of atherosclerosis in patients with increased ROS, such as in diabetes, obesity or hypertension [11] and ameliorate hyperglycemia-induced endothelial dysfunction [12]. Furthermore, UCP-2 might be playing an important role in the regulation of energy expenditure and are likely to contribute to obesity and type 2 diabetes mellitus (T2DM). In this regard, several UCP-2 gene polymorphisms were linked to an increased body weight index or obesity in Pima Indians [13,14] and in Balinese population [15] or with insulin resistance or T2DM [16-18]. Thus, reduced UCP gene expression has been found in adipose tissue of obese subjects and in the first-degree relatives of T2DM patients. On the other hand, both obese and diabetic patients have associated vascular complications such as atherosclerosis $[19,20]$, insulin resistance with hyperinsulinemia and elevated circulating TNF- $\alpha$ levels [21]. To get a new insight on that UCP-2 protective effect on the vasculature, we have studied new molecular mechanisms that help to explain whether the moderate hyperinsulinemia or reduction TNF- $\alpha$ levels might have a protective role against vascular damage mediated by UCP-2 modulation. Firstly, we have analyzed the effect of insulin and/or TNF- $\alpha$ on UCP-2 levels in endothelial and vascular smooth muscle cells. After that, we wondered if some mechanisms studied in vitro could be of any relevance in vivo. We used the following experimental models: $\mathrm{ApoE}^{-/-}$mice at $8,12,18$ or 24 weeks of age, BATIRKO mice under high-fat diet for 16 weeks and 52-wk-old
BATIRKO mice with o without anti-TNF- $\alpha$ treatment to address the relationship between UCP-2 expression, or lipid accumulation, or vascular damage, or oxidative stress, or insulin or TNF- $\alpha$ plasma levels. Finally, we searched the role of iNOS in the inhibition of UCP-2 expression by TNF- $\alpha$.

\section{Methods \\ Cell culture}

Primary vascular smooth muscle cells (VSMC) were obtained from thoracic aorta arteries, immortalized and cultured as described previously [22]. Endothelial cell line, SVEC4-10EE2 (clone 2167) was purchased from ATCC and was cultured in DMEM medium supplemented with $10 \%$ of horse bovine serum, respectively. Both cell lines were growth-arrested by incubation in medium without serum for $5 \mathrm{~h}$, and then incubated with the corresponding stimuli. For experiments in vitro, we have used TNF- $\alpha(10 \mathrm{ng} / \mathrm{mL})$, insulin $(10 \mathrm{nmol} / \mathrm{L})$, oleate $(1 \mathrm{mmol} / \mathrm{L})$ and L-NAME $(1 \mathrm{mmol} / \mathrm{L})$.

\section{Experimental models}

Male mice were maintained in the Animal Care Facility under the standard conditions of temperature and $12 \mathrm{~h}$ light/dark cycle. All animals from three experimental models used are under C57BL/6 genetic background. Male $\mathrm{ApoE}^{-1-}$ knockout mice and their control mice were fed a Western type diet (A04 + 21\% kcal from fat) at six week-age for $2,6,12$ or 18 weeks respectively. Male BATIRKO mice [22] were fed on high-fat diet $(\mathrm{A} 04+61 \% \mathrm{kcal}$ from fat) for 16 weeks or standard diet ( $3 \%$ calories from fat, A04) for 52 weeks. Moreover, one group of 52-wk-old BATIRKO mice were treated with LEAF purified anti-TNF- $\alpha$ (MP6-XT22, Bio-Legend, San Diego, CA) (50 $\mu \mathrm{g} /$ mouse ip.) every 3 days for 6 weeks as previously described [23]. All animal experimentation described in this manuscript was conducted according with accepted standards of human animal care, as approved by the corresponding institutional committee. The investigation also conforms to the Guide for the Care and Use of Laboratory Animals published by the National Institutes of Health (NIH Publication No. 85-23, revised 1996) and in accordance with The ARRIVE Guideline for Reporting Animal research [24].

\section{Western blot}

Western blot analyses were performed on protein extracts from VSMCs, ECs or aorta artery as previously described [25]. The antibodies used were anti-phospho-AKT (T308), AKT, p-p70S6K (T389), p70S6K, p-p44/42 (S202/ T204) and $p 44 / 42$ from Cell Signalling, anti-UCP-2 was from Calbiochem and anti- $\beta$-actin or $\alpha$-tubulin was from Sigma-Aldrich Corp. 


\section{RNA extraction and real-time quantitative PCR}

Total RNA was extracted from ECs, VSMCs or aorta artery from mice by TRIzol method (Invitrogen, Carlsbad, CA). The gene expression was analyzed by real-time quantitative PCR (qRT-PCR) as described [25].

\section{Analytical procedures}

Plasma levels of insulin and TNF- $\alpha$ were analyzed using ELISA kits (Millipore and SABioSciences, Frederick, $\mathrm{MD}$, respectively).

\section{Histological analysis}

Aortic roots were OCT-embedded and sections of $7 \mu \mathrm{m}$ interval were Oil-Red-O/hematoxylin stained was done to measure lipid depot. The lesion size on aortic root was also measured as described [22]. Macrophages and nitrotyrosine levels were detected by immunoperoxidase with rat anti-mouse F4/80 antigen (MCA497GA, AbD serotec) and rabbit anti-nitrotyrosine polyclonal $\mathrm{Ab}$ (06-284, Upstate), respectively.

\section{Statistical analysis}

All values were expressed as means $+/-$ sem. Data were analyzed using a one-way analysis of variance, followed by a Bonferroni test if differences were noted (SPSS 15.0 program). Spearman's correlation coefficient analysis was used to assess associations between several parameters of experimental model. The null hypothesis was rejected when the $\mathrm{p}$ value was less than 0.05 .

\section{Results}

Differential effect of TNF-alpha and Insulin on UCP-2 expression in vascular cells

Although it is well-known the protective role of UCP-2 against vascular damage [10], the relationship between insulin or TNF- $\alpha$ with UCP-2 in vascular cells is completely unknown. Thus, we addressed that issue in ECs and VSMCs as two major components of the vascular wall. Firstly, we observed that insulin significantly increased UCP-2 protein levels at 4, 8 and $18 \mathrm{~h}$ in ECs and at $1 \mathrm{~h}$ through $24 \mathrm{~h}$ in VSMCs (Figure 1A). We ascertained that the pre-treatment with $10 \mathrm{ng} / \mathrm{mL}$ TNF- $\alpha$ for 2 hours induced insulin resistance in both vascular cells as shown by the significant decreases in the phosphorylation of Akt, p70S6K and p44/42 in cells stimulated with $10 \mathrm{nmol} / \mathrm{L}$ insulin for 10 minutes (Figure 1B). Based on these data, we analyzed the effect of TNF- $\alpha$ on UCP-2 protein levels. Thus, $10 \mathrm{ng} / \mathrm{mL}$ TNF- $\alpha$ for 2 hours downregulated UCP-2 protein levels in both vascular cells respectively (Figure 1C and E). More importantly, we also demonstrated that TNF$\alpha$ pre-treatment induced a significant decrease of UCP-2 protein levels in VSMCs and ECs stimulated upon insulin action for $4 \mathrm{~h}$ or $18 \mathrm{~h}$, respectively (Figure $1 \mathrm{C}$ ). At this stage, we compared insulin effect with a well-known inductor of UCP-2 expression such as oleate [26]. Firstly, we observed a significant increase in UCP-2 expression at mRNA or protein level at $18 \mathrm{~h}$ upon oleate treatment in both vascular cell lines respectively (Figure 1D and E). However, TNF- $\alpha$ pre-treatment did not significantly impair UCP-2 protein induced by oleate in both vascular cells respectively (Figure 1E).

\section{Protective role of UCP-2 against lipid accumulation and vascular damage}

At this step, we wondered if some mechanisms described in vitro could be of any relevance in vivo. Thus, we explored in vivo the associations between UCP-2 levels and lipid accumulation, or vascular damage, or oxidative stress, or TNF- $\alpha$ levels in the aortic wall, or with circulating insulin levels. We used different mouse models of disease. The first one was $\mathrm{ApoE}^{-1-}$ mice and their controls at 8, 12, 18 and 24 wk of age. By Oil-Red-O/ hematoxylin staining, we observed that $\mathrm{ApoE}^{-/-}$mice developed progressively higher lesion area with higher lipid content within aortic roots (Figure 2A). We also analyzed by qRT-PCR UCP-2 mRNA expression and its likely relationship with the lesion area or lipid content. Thus, UCP-2 levels augmented significantly within the aorta from 8 week-old $\mathrm{ApoE}^{-/-}$mice as compared with their corresponding controls (Figure 2B). However, UCP-2 levels sharply decreased from 12- through 24-wk-old $\mathrm{ApoE}^{-1-}$ mice (Figure 2B). Thus, we established a negative and significant correlationship between UCP-2 levels and lesion area or lipid depot within the aortic wall (Figure 2C). Additionally, we checked that UCP-2 protein levels were also decreased in 24-wk-old $\mathrm{ApoE}^{-/-}$mice in relation to theirs controls (Additional file 1: Figure S1A).

The second mouse-model studied was BATIRKO mice under HFD for 16 weeks. These mice lacking IR in BAT-specific manner under STD showed severe brown lipoatrophy, susceptibility to the obesity (mainly in gonadal WAT compartment), glucose intolerance and a defect in insulin secretion [22,27]. Moreover, BATIRKO mice under HFD also showed insulin resistance and more severe glucose intolerance. So, we have phenotypically established two groups of obese BATIRKO mice as characterized by their plasma insulin levels, pancreatic islet area, islet insulin content, and also by their glucose tolerance curves and fasting hyperglycemia. The first group showed compensated insulin resistance (moderately hyperinsulinemic, BATIRKO $\mathrm{MH}$, fasted insulin plasma levels $=1.4 \pm 0.2 \mathrm{ng} / \mathrm{mL}, \mathrm{p}<0.05$ vs. control group), marked pancreatic beta cell hyperplasia $(0.06 \pm 0.01$ islet area/pancreas area, $\mathrm{p}<0.05$ vs. control group) and higher islet insulin content $(0.28 \pm 0.02$ positive staining/ islet area, $\mathrm{p}<0.05$ vs. control group). A second group showed non-compensated insulin resistance (normoinsulinemic, BATIRKO N, fasted insulin plasma 


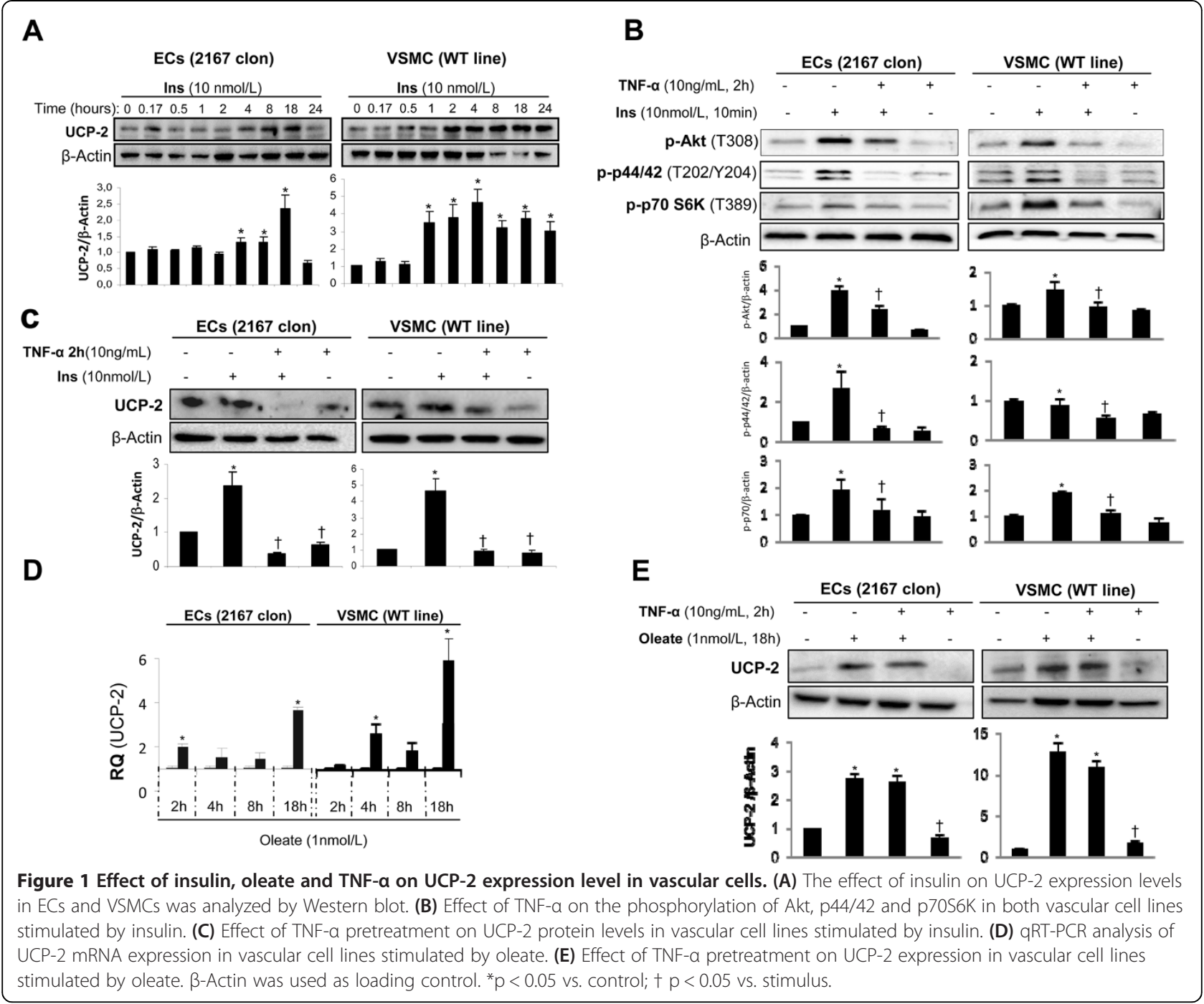

levels $=0.42 \pm 0.05 \mathrm{ng} / \mathrm{mL}, \mathrm{p}<0.05$ vs. BATIRKO $\mathrm{MH}$ ), normal islet size $(0.02 \pm 0.008$ islet area/pancreas area, ns. vs. control group) and lower islet insulin content $(0.14 \pm 0.01$ positive staining/islet area, $\mathrm{p}<0.05$ vs. control group). In addition, normoinsulinemic obese BATIRKO mice $(\mathrm{N})$ showed a more severe glucose intolerance and mild fasting hyperglycemia as compared with moderate hyperinsulinemic obese BATIRKO mice $(\mathrm{MH})$ (Fasting glycemia from BATIRKO $\mathrm{N}=138 \pm 9 \mathrm{mg} / \mathrm{dL}, \mathrm{p}<0.05$ vs. control group; fasting glycemia from BATIRKO $\mathrm{MH}=$ $123 \pm 8 \mathrm{mg} / \mathrm{dL}$ and from control group $=111 \pm 4 \mathrm{mg} / \mathrm{dL}$ ). Under this scenario, we observed that BATIRKO $\mathrm{MH}$ mice showed a significant increase of UCP-2 levels as compared with control or BATIRKO N mice respectively (Figure 3A and Additional file 1: Figure S1B). At this stage, we explored the relationship between UCP-2 levels within the aortic wall and the vascular damage. Thus, normoinsulinemic obese BATIRKO mice with lower UCP-2 levels in the aorta showed endothelial dysfunction
(Additional file 2: Figure S2A), higher vasoconstrictor response to angiotensin II or $\mathrm{TXA}_{2}$ (Additional file 2: Figure S2B), higher lipid depots (Figure 3B), higher lesion area and macrophage infiltration in aortic roots (Additional file 2: Figure S2C) as compared with moderate hyperinsulinemic BATIRKO mice. Moreover, we also observed a significant negative correlationship between UCP-2 levels and lipid depots or lesion area in the aorta in those animals (Figure 3B).

\section{Relationship between TNF- $\alpha$ and UCP-2 expression levels in vivo}

As we had demonstrated in vitro that TNF- $\alpha$ might downregulate UCP-2 protein levels in vascular cells, we explored that mechanism in both groups of obese BATIRKO mice in the aorta (Figure 3C). Normoinsulinemic obese BATIRKO mice (N) with lower UCP-2 levels in aorta and higher vascular damage showed a significant increase in TNF- $\alpha$ plasma levels, or expressed in WAT or 


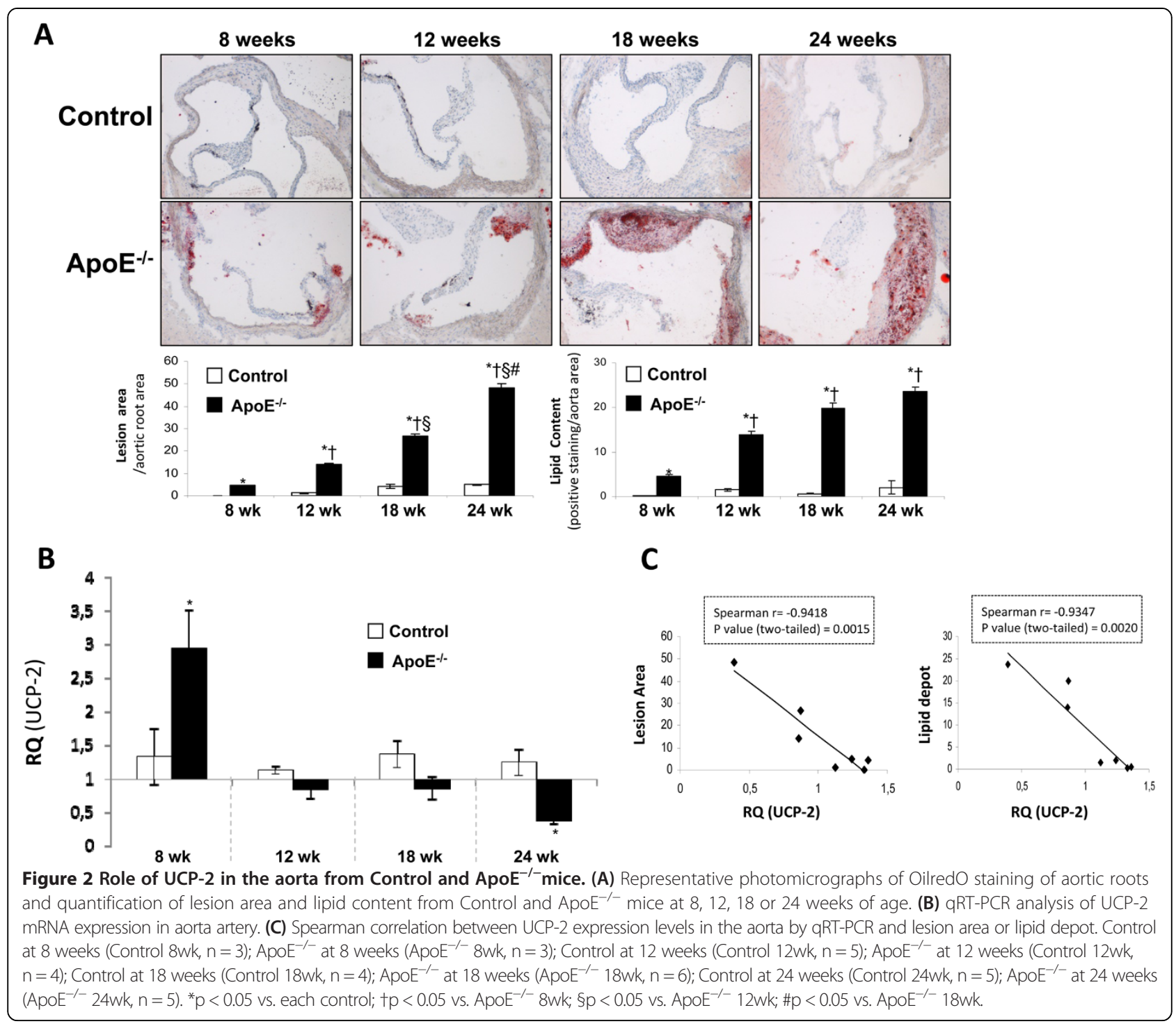

aorta as compared with moderate hyperinsulinemic BATIRKO mice $(\mathrm{MH})$ (Figure $3 \mathrm{C}$ ). Thus, we observed a significant negative correlationship between UCP-2 and TNF- $\alpha$ levels in the aorta (Figure 3D). We also explored those levels in 52-week-old BATIRKO mice under standard diet. Those mice showed severe brown lipoatrophy, obesity, hypoinsulinemia, mild fasting hyperglycemia, glucose intolerance, vascular dysfunction, macrophage infiltration, oxidative stress, and a significant increase of gene markers of endothelial activation and inflammation as previously characterized [23], TNF- $\alpha$ playing a major role [23]. Now, we have observed that 52- week-old BATIRKO mice show a significant reduction of UCP-2 expression levels, that UCP-2 lowering in the aorta was precluded by the pre-treatment with anti-TNF- $\alpha$ (Figure 4A and Additional file 1: Figure S1C and D). In addition, a significantly negative correlationship between UCP- 2 and TNF- $\alpha$ expression levels in the aorta was also observed (Figure 4B).

\section{Effect of insulin on UCP-2 expression levels in vivo}

At this step, we wondered if UCP-2 overexpression induced by insulin in vitro could be of any relevance in vivo. For this purpose, we observed that obese BATIRKO mice with moderate hyperinsulinemia had higher UCP-2 levels in aorta and lesser vascular damage than normoinsulinemic obese BATIRKO mice (Figure 3A, B and E and Additional file 1: Figure S1B). Moreover, we established a positive and significant correlation between circulating insulin levels and UCP-2 levels in aorta (Figure 3F). In the third experimental model, we also observed this correlationship between insulin and UCP-2 expression levels (Figure 4C). Thus, 52-week-old control group displaying moderate hyperinsulinemia showed a significant increase in UCP-2 expression levels in the aorta (Figure 3A and Additional file 1: Figure S1D). However, 52-week-old BATIRKO mice showing a lower insulinemia manifested a significant reduction of UCP-2 expression 


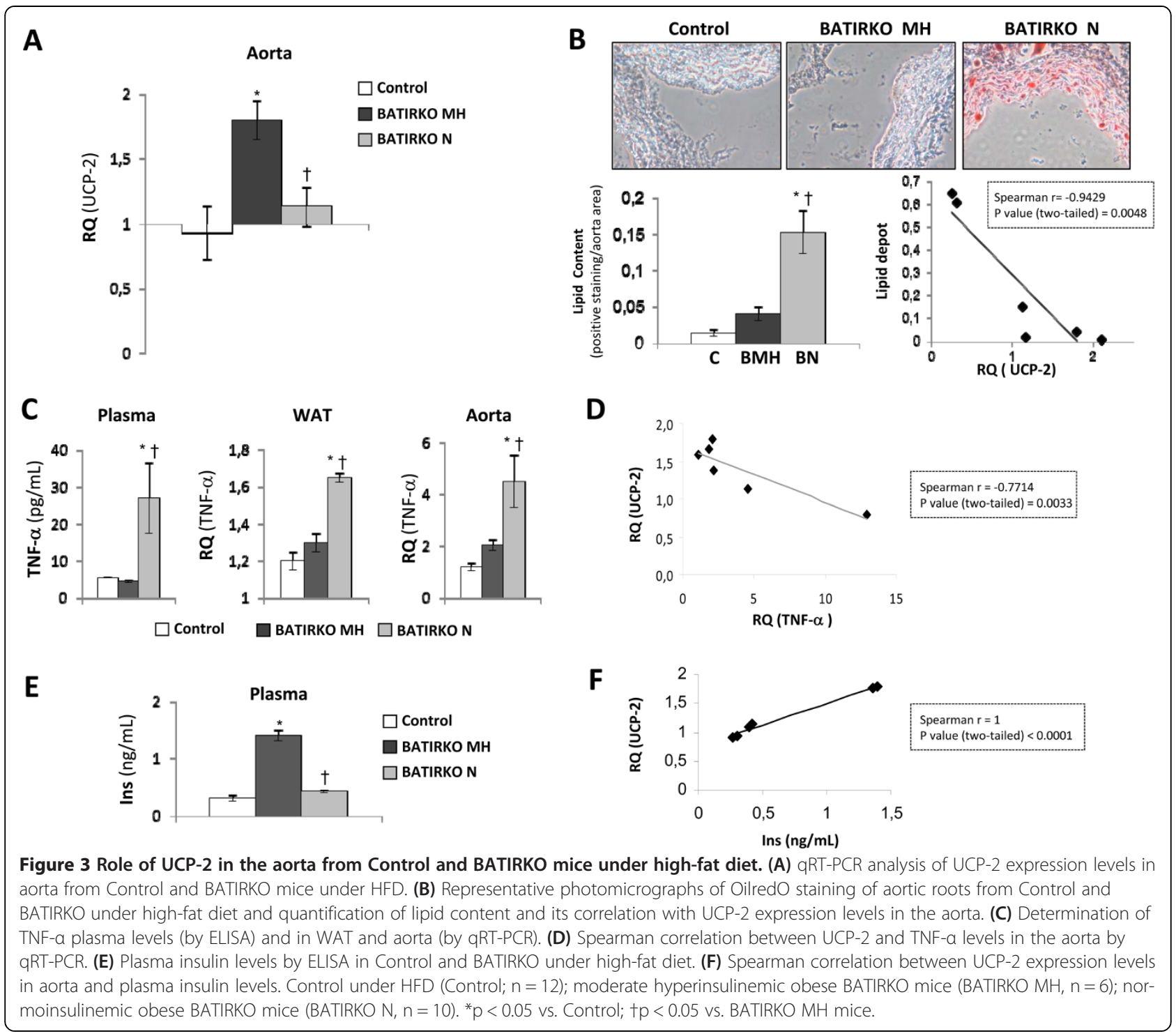

levels and higher vascular alterations (Figure 3A and Additional file 1: Figure S1C and D). On the other hand, UCP-2 might modify atherosclerotic process due to the fact that elevated levels of this protein reduce ROS levels [11]. Thus, we observed a significant decrease of superoxide anion and nitrotyrosine levels in aortic roots from moderate hyperinsulinemic as compared with normoinsulinemic obese BATIRKO mice (Additional file 2: Figure S2C).

\section{Role of iNOS in the UCP-2 downregulation induced by TNF-a}

Back to in vitro studies, we explored whether the reduction in UCP-2 levels in the aorta induced by TNF- $\alpha$ might be mediated at least in part by iNOS in vascular cells. Thus, we observed by qRT-PCR that TNF- $\alpha$ treatment for 2, 4 and 8 hours induced a significant robust increase of iNOS mRNA expression in vascular cells (Figure 5A). Next step, we observed that the pre-treatment with iNOS inhibitor (L-NAME) impaired that rising of the UCP-2 expression levels in ECs or VSMCs in response to TNF- $\alpha$ (Figure 5B). These data strongly suggest that TNF- $\alpha$ downregulates UCP-2 expression levels through iNOS expression in the aortic wall. We explored that relationship between iNOS and UCP-2 in vivo. Thus, we observed that 18 -week-old and mainly 24-week-old $\mathrm{ApoE}^{-/-}$mice showed a significant increase of iNOS expression levels together with a significant reduction of UCP-2 levels in the aorta (Figure 5C). Moreover, normoinsulinemic obese BATIRKO mice with lower UCP-2 levels and higher vascular damage showed a significant increase of iNOS levels as compared with moderate hyperinsulinemic BATIRKO mice in the aorta (Figure 5D). 

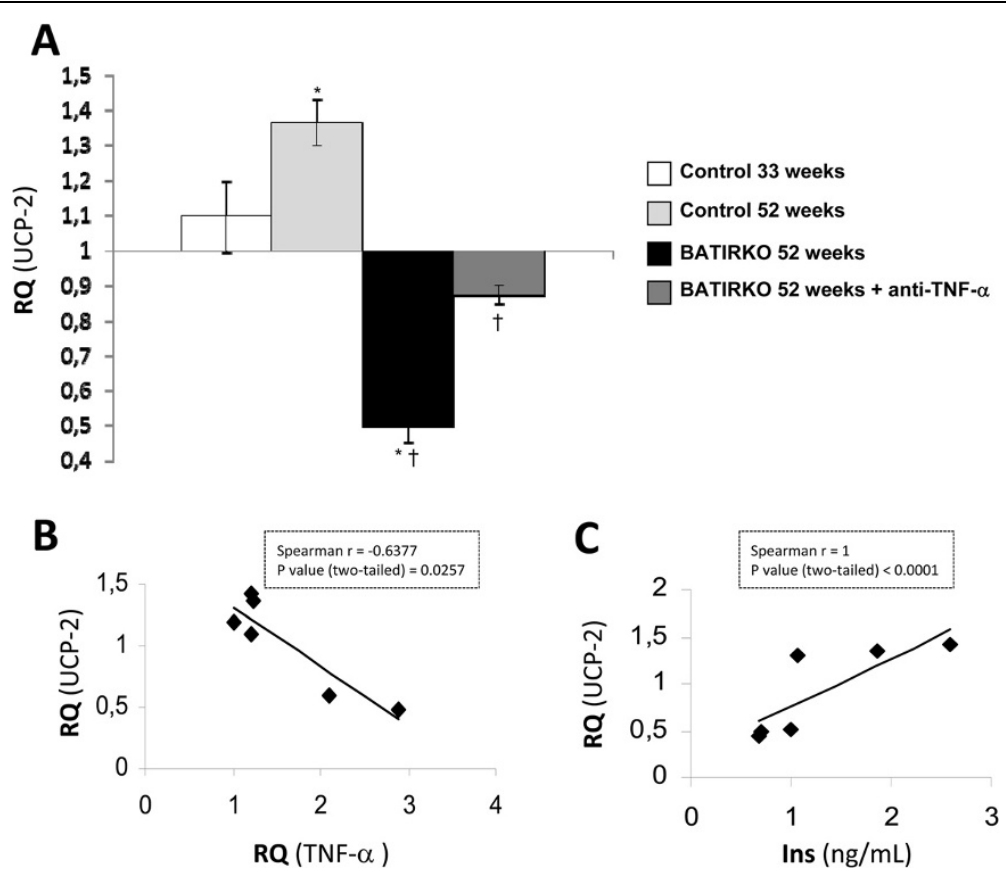

Figure 4 Effect of anti-TNF-a pre-treatment on UCP-2 expression level in BATIRKO mice. (A) qRT-PCR analysis of UCP-2 mRNA expression in aorta from Control and BATIRKO mice and anti-TNF-a treated BATIRKO mice at 52 weeks of age. Spearman correlation between UCP-2 expression levels and TNF-a in the aorta (B), or with plasma insulin levels (C). Control 33 weeks $(n=12)$; Control 52 weeks $(n=12)$; BATIRKO 52 weeks $(n=8)$; BATIRKO 52 weeks + anti-TNF- $a(n=3) .{ }^{*} p<0.05$ vs. Control; $+p<0.05$ vs. 52-wk-old-BATIRKO mice.
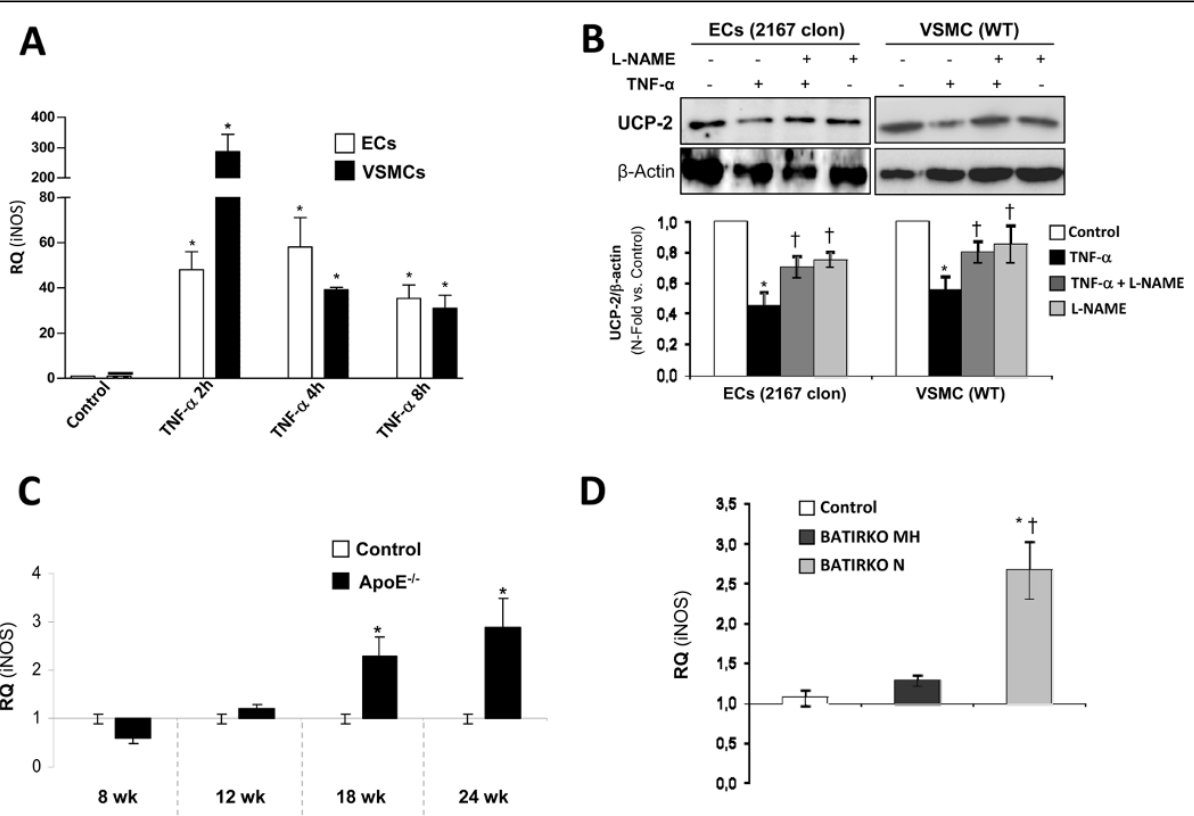

D

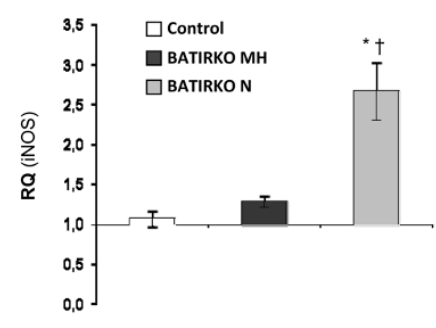

Figure 5 Role of iNOS in the inhibition of UCP-2 expression level induced by TNF-a. (A) qRT-PCR analysis of iNOS mRNA expression in ECS and VSMCS stimulated with TNF-a for 2, 4 and 8 hours. (B) Western blot analysis of UCP-2 levels with or without iNOS inhibitor (L-NAME) in ECS and VSMCs stimulated with TNF-a. ${ }^{*} p<0.05$ vs. control; $\uparrow p<0.05$ vs. stimuli. qRT-PCR analysis of iNOS mRNA expression in aorta from Control and Apo $^{-/-}$mice at 8, 12, 18 and 24 wk of age (C) and Control and BATIRKO mice under high-fat diet (D). * $p<0.05$ vs. Control; $\uparrow p<0.05$ vs. BATIRKO $\mathrm{MH}$ mice. 


\section{Discussion}

Protector role of UCP-2 against lipid depot and vascular damage

Atherosclerosis is a multi-factorial chronic vascular inflammatory disease characterized by endothelial dysfunction and accumulation of lipids, inflammatory cells, smooth muscle cells and extracellular matrix in the arterial neointima [28]. Several studies suggest that ROS are involved in plaque formation [29] and all plaque cellular components may respond to and be damaged by ROS, contribute to plaque progression and finally, to plaque rupture [30]. Thus, several approaches to stop ROS production and to alter disease progression have been used [31,32]. In addition, it has been previously published that UCP-2 overexpression in macrophages decreases intracellular ROS levels and reduces their immune activity $[33,34]$. Moreover, UCP-2 might function as an adaptive antioxidant defense to protect against the development of atherosclerosis in response to high fat and cholesterol diet [35] and improve hyperglycemia-induced endothelial dysfunction [12]. Under this scenario, our results demonstrate that high-fat diet BATIRKO mice showing lower UCP-2 expression levels manifested higher oxidative stress in the aorta. Moreover, the decrease in UCP-2 levels in the aorta is strongly inversely correlated with lipid accumulation and lesion area from 24-week-old ApoE ${ }^{-/-}$ mice or normoinsulinemic BATIRKO mice in the aorta. Previous results have also suggested a protective role of UCP-2 against atherosclerosis [10] showing an antiatherogenic effect in macrophages, ECs and VSMCs [11]. Thus, UCP-2 higher expression reduced proliferation, migration and plasminogen activator 1 expression in human VSMCs [36].

\section{Insulin induces UCP-2 overexpression in aorta protecting against vascular damage}

A better knowledge of UCP-2 expression levels regulation in the vasculature may improve the management of the atherosclerotic process. Thus, we explored the association between insulin and UCP-2 in vivo and in vitro. Our results suggest that insulin or moderate hyperinsulinemia in response to insulin resistance induces UCP-2 expression in ECs and VSMCs or in the aorta from BATIRKO $\mathrm{MH}$ mice respectively. On this regard, we previously demonstrated that insulin or IGF-1 induce UCP-1 expression through IRS-1 or AP-1 activity in a PI3K/Akt dependent manner [37,38]. Others authors had also described similar effects of insulin on UCP-2 expression levels in bovine retinal microvascular endothelial cells [39] or in skeletal muscle [40]. Moreover, it have been described that intensive insulin therapy suppressed iNOS gene expression in liver and skeletal muscle, possibly in part via reduced NF- $\mathrm{kB}$ activation, and lowered the elevated circulating NO levels [41]. So, insulin might also reduced NF-кB activation and iNOS levels in aorta and in consequence favours UCP-2 overexpression and protect against vascular damage.

\section{TNF- $a$ downregulates UCP-2 in aorta accelerating vascular damage}

Among several proinflammatory and proatherogenic signals working on the vasculature TNF- $\alpha$ is relevant the most. Thus, the relationship between TNF- $\alpha$ and UCP-2 expression levels appears to be of importance in assessing vascular damage risk. On this regard, we have shown that insulin and TNF- $\alpha$ have antagonistic effect on UCP-2 expression in ECs and VSMCs. It has been previously published that proinflammatory cytokines such as TNF- $\alpha$ and/or IL-1 $\beta$ downregulated UCP-2 levels in adipocytes [42], INS-1 cells or rat pancreatic islets [43]. Moreover, our data provide a strong support in vivo to the negative relationship between TNF- $\alpha$ and UCP-2. Thus, 52-week-old BATIRKO mice or normoinsulinemic BATIRKO mice under high-fat diet with lower UCP-2 levels showed elevated TNF- $\alpha$ expression levels in WAT, plasma and aorta. Moreover, TNF- $\alpha$ may directly downregulates adiponectin [44] contributing to the development of vascular insulin resistance and the decrease of UCP-2 levels in the aorta. On this regard, it has previously been described that adiponectin induces UCP-2 expression in the liver [45]. In the two populations of BATIRKO mice, we observed a negative correlation between TNF- $\alpha$ and adiponectin levels in both WAT and plasma. Therefore, higher levels of adiponectin might induce UCP-2 overexpression in the aorta attenuating vascular damage. The use of the anti-TNF- $\alpha$ antibody pre-treatment support the concept that TNF- $\alpha$ downregulates UCP-2 expression levels as shown in 52-week-old BATIRKO mice.

Other mechanism involved in the inhibitory effect of TNF- $\alpha$ on UCP-2 expression levels is the NO-dependent pathway induction of iNOS expression in ECs and VSMCs as previously described in 3T3F442A preadipocytes [42]. In vivo, we also demonstrated that anti-TNF- $\alpha$ treatment in 52-week-old BATIRKO mice is able to reduce NF- $\mathrm{kB}$ activation in white and brown adipose tissues and aorta, reducing iNOS levels in aorta [24] and increasing UCP-2 levels in aorta and as result lowering vascular damage. Moreover, LPS promoted the expression of iNOS and ROS production as well as inflammatory cytokines in UCP-2 ${ }^{-/-}$macrophages [46,47]. Our data strongly suggest an inverse correlationship between iNOS and UCP-2. Thus, 24-week-old ApoE ${ }^{-/-}$mice, normoinsulinemic BATIRKO mice under high-fat diet and 52-week-old BATIRKO mice with lower UCP-2 levels had higher iNOS levels and higher vascular damage. In addition, anti-TNF- $\alpha$ antibody pre-treatment reduced iNOS expression, restoring UCP-2 levels, and improving vascular alterations from 52-week-old BATIRKO mice [24]. 


\section{Conclusions}

In conclusion, our results suggest that insulin and TNF- $\alpha$ share an antagonistic effect on UCP-2 expression levels in vascular cells and also in the aorta in vivo. Thus, moderate hyperinsulinemia in response to insulin resistance or lowering of TNF- $\alpha$ levels within the aorta attenuates vascular damage, this protective effect being mediated by UCP-2 expression levels through iNOS.

\section{Additional files}

Additional file 1: Figure S1. UCP-2 protein expression in vivo. UCP-2 protein levels were detected by Western blot and a-tubulin was used as loading control. UCP-2 protein levels in aorta artery from Control and $\mathrm{ApoE}^{-/-}$mice at 24 weeks of age (A), Control, moderate hyperinsulinemic obese BATIRKO and normoinsulinemic obese BATIRKO under HFD (B), Control at 33 weeks of age, Control and BATIRKO and 52 weeks of age (C) and anti-TNF-a treated BATIRKO mice at 52 weeks of age (D). (A) Control at 24 weeks of age $(C 24 ; n=3) ; A p o E^{-/-}$mice at 24 weeks of age

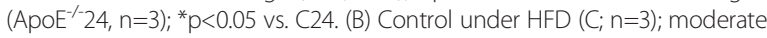
hyperinsulinemic obese BATIRKO mice $(\mathrm{BMH}, \mathrm{n}=3)$; normoinsulinemic obese BATIRKO mice ( $B N, n=3)$. $+p<0.05$ vs. BMH mice. ( $C$ and D) Control 33 weeks $(C 33, n=3)$; Control 52 weeks (C52, n=6); BATIRKO 52 weeks (B52w, n=5); BATIRKO 52 weeks + anti-TNF-a (B52+anti-TNF- $a, n=3) .+p<0.05$ vs. C52; $\# \mathrm{p}<0.05$ vs. B52.

Additional file 2: Figure S2. Characterization of vascular damage in BATIRKO mice under high-fat diet. (A) Vascular function was studied in aortic rings from control and BATIRKO mice under HFD. We evaluated endothelium-dependent relaxations to acetylcholine (Ach; $10^{-5} \mathrm{~mol} / \mathrm{L}$ ) and endothelium-independent relaxations induced by sodium nitroprusside (SNP; $\left.10^{-7} \mathrm{~mol} / \mathrm{L}\right)$ in phenylephrine $\left(10^{-6} \mathrm{~mol} / \mathrm{L}\right)$ precontracted rings. (B) Contractile responses to thromboxane $\mathrm{A} 2$ analogue (U46619; $10^{-6} \mathrm{~mol} / \mathrm{L}$ ) and Angiotensin II (Ang $\|, 10^{-6} \mathrm{~mol} / \mathrm{L}$ ) in aortic rings from controls and BATIRKO mice. (C) (Left) Representative photomicrographs of macrophages immunohistochemistry (F4/80) (first file of panels), of nitrotyrosine levels by immunohistochemistry $(\mathrm{IHC}$ ) (second file of panels) and of superoxide anion levels in situ by hydroethidine method (third file of panels) in aortic roots from control and BATIRKO mice. (Right) Quantitative analysis of lesion area, macrophage infiltration, superoxide levels and of nitrotyrosine expression in aortic roots from control and BATIRKO mice. Results are expressed as mean \pm SEM. Control $(n=12)$, BATIRKO MH $(n=6)$, BATIRKO $N(n=10) .{ }^{*} p<0.05$ vs. Control; $+p<0.05$ vs. BATIRKO MH mice.

\section{Abbreviations}

Ach: Acetylcholine; Ang II: Angiotensin II; Akt: Protein kinase B (Pkb); $\mathrm{ApoE}^{-/-}$mice: Apolipoprotein E knockout mice; BAT: Brown adipose tissue; BATIRKO: BAT-specific IR knockout mice; BATIRKO MH: Moderate hyperinsulinemic obese BATIRKO mice; BATIRKO N: Normoinsulinemic obese BATIRKO mice; ECs: Endothelial cell lines; L-NAME: Nitro-L-arginine methyl ester hydrochloride- NOS inhibitor; HFD: High-fat diet; IGF-1: Insulin-like growth factor-1; iNOS: Inducible nitric oxide synthase; IR: Insulin receptor; NF-kB: Nuclear factor kappa B; ROS: Reactive oxygen species; SNP: Sodium nitroprusside; STD: Standard diet; TNF-a: Tumor necrosis factor alpha; TXA2: Thromboxane A2; UCP-2: Uncoupling protein 2; U46619: TXA2 analogue; VSMCs: Vascular smooth muscle cells; WAT: White adipose tissue; wk: week.

\section{Competing interests}

The authors have nothing to disclose.

\section{Authors' contributions}

AG-H: has participated to the acquisition of data in vitro e in vivo, analysis and interpretation of data and in the design of study and its coordination and in the statistical analysis as well as writing the paper. LP, NB, OE, YFO, CG and SD-C: have participated to the acquisition of data in vitro e in vivo, analysis and interpretation of data. NH, VC and VL: have participated in the analysis of vascular function from experimental models and helped to draft the manuscript. BG-L: has participated to the acquisition of data in vitro. MB: has participated in the design of the study and its coordination and writing the manuscript. All authors have read and approved the final manuscript.

\section{Acknowledgments}

The authors thank Gema García-Gómez and Silvia Fernández for technical assistance. This work was supported by grants SAF2008/00031 and SAF2011/22555 from MCINN, Comunidad de Madrid (S2010/BMD-2423) and CIBERDEM ISCIII, Spain.

\section{Author details}

1 Biochemistry and Molecular Biology Department, School of Pharmacy, Complutense University of Madrid, Madrid, Spain. ${ }^{2}$ CIBER of Diabetes and Associated Metabolic Diseases, Madrid, Spain. ${ }^{3}$ Almudena Gómez-Hernández, Biochemistry and Molecular Biology Department, School of Pharmacy, Complutense University of Madrid, Madrid 28040, Spain. ${ }^{4}$ Physiology Department, School of Medicine, Complutense University of Madrid, Madrid, Spain.

Received: 23 April 2014 Accepted: 27 June 2014

Published: 31 July 2014

\section{References}

1. Diano $S$, Horvath TL: Mitochondrial uncoupling protein 2 (UCP2) in glucose and lipid metabolism. Trends Mol Med 2012, 18:52-58.

2. Dalgaard LT, Pedersen O: Uncoupling proteins: functional characteristics and role in the pathogenesis of obesity and Type II diabetes. Diabetologia 2001, 44:946-965.

3. Klingenberg M, Huang SG: Structure and function of the uncoupling protein from brown adipose tissue. Biochim Biophys Acta 1999, 1415:271-296.

4. Gimeno RE, Dembski M, Weng X, Deng N, Shyjan AW, Gimeno CJ, Iris F, Ellis SJ, Woolf EA, Tartaglia LA: Cloning and characterization of an uncoupling protein homolog: a potential molecular mediator of human thermogenesis. Diabetes 1997, 46:900-906.

5. Boss O, Samec S, Paoloni-Giacobino A, Rossier C, Dulloo A, Seydoux J, Muzzin P, Giacobino JP: Uncoupling protein-3: a new member of the mitochondrial carrier family with tissue-specific expression. FEBS Lett 1997, 408:39-42.

6. Fleury C, Neverova M, Collins S, Raimbault S, Champigny O, Levi-Meyrueis C, Bouillaud F, Seldin MF, Surwit RS, Ricquier D, Warden CH: Uncoupling protein-2: a novel gene linked to obesity and hyperinsulinemia. Nat Genet 1997, 15:269-272.

7. Arsenijevic D, Onuma H, Pecqueur C, Raimbault S, Manning BS, Miroux B, Couplan E, Alves-Guerra MC, Goubern M, Surwit R, Bouillaud F, Richard D, Collins S, Ricquier D: Disruption of the uncoupling protein-2 gene in mice reveals a role in immunity and reactive oxygen species production. Nat Genet 2000, 26:435-439.

8. Vidal-Puig AJ, Grujic D, Zhang CY, Hagen T, Boss O, Ido Y, Szczepanik A, Wade J, Mootha V, Cortright R, Muoio DM, Lowell BB: Energy metabolism in uncoupling protein 3 gene knockout mice. J Biol Chem 2000, 275:16258-16266.

9. Gong DW, Monemdjou S, Gavrilova O, Leon LR, Marcus-Samuels B, Chou CJ, Everett C, Kozak LP, Li C, Deng C, Harper ME, Reitman ML: Lack of obesity and normal response to fasting and thyroid hormone in mice lacking uncoupling protein-3. J Biol Chem 2000, 275:16251-16257.

10. Blanc J, Alves-Guerra MC, Esposito B, Rousset S, Gourdy P, Ricquier D, Tedqui A, Miroux B, Mallat Z: Protective role of uncoupling protein 2 in atherosclerosis. Circulation 2003, 107:388-390.

11. Kim HS, Park KG, Koo TB, Huh S, Lee IK: The modulating effects of the overexpression of uncoupling protein 2 on the formation of reactive oxygen species in vascular cells. Diabetes Res Clin Pract 2007, 77:S46-S48.

12. Sun J, Pu Y, Wang P, Chen S, Zhao Y, Liu C, Shang Q, Zhu Z, Liu D: TRPV1-mediated UCP2 upregulation ameliorates hyperglycemia-induced endothelial dysfunction. Cardiovasc Diabetol 2013, 12:69

13. Millet L, Vidal H, Andreelli F, Larrouy D, Riou JP, Ricquier D, Laville M, Langin D: Increased uncoupling protein-2 and -3 mRNA expression during fasting in obese and lean humans. J Clin Invest 1997, 100:2665-2670.

14. Bao S, Kennedy A, Wojciechowski B, Wallace P, Ganaway E, Garvey WT: Expression of mRNAs encoding uncoupling proteins in human skeletal muscle: effects of obesity and diabetes. Diabetes 1998, 47:1935-1940. 
15. Oktavianthi S, Trimarsanto H, Febinia CA, Suastika K, Saraswati MR, Dwipayana P, Arindrarto W, Sudoyo H, Malik SG: Uncoupling protein 2 gene polymorphisms are associated with obesity. Cardiovasc Diabetol 2012, 11:41.

16. Wang H, Chu WS, Lu T, Hasstedt SJ, Kern PA, Elbein SC: Uncoupling protein-2 polymorphisms in type 2 diabetes, obesity, and insulin secretion. Am J Physiol Endocrinol Metab 2004, 286:E1-E7.

17. Shen H, Qi L, Tai ES, Chew SK, Tan CE, Ordovas JM: Uncoupling protein 2 promoter polymorphism -866G/A, central adiposity, and metabolic syndrome in Asians. Obesity 2006, 14:656-661.

18. D'Adamo M, Perego L, Cardellini M, Marini MA, Frontoni S, Andreozzi F, Sciacqua A, Lauro D, Sbraccia P, Federici M, Paganelli M, Pontiroli AE, Lauro R, Perticone F, Folli F, Sesti G: The -866A/A genotype in the promoter of the human uncoupling protein 2 gene is associated with insulin resistance and increased risk of type 2 diabetes. Diabetes 2004, 53:1905-1910.

19. Badimon L, Hernández Vera R, Vilahur G: Atherothrombotic risk in obesity. Hamostaseologie 2013, 33:259-268.

20. Haffner SM, Lehto S, Rönnemaa T, Pyörälä K, Laakso M: Mortality from coronary heart disease in subjects with type 2 diabetes and in nondiabetic subjects with and without prior myocardial infarction. N Engl J Med 1998, 339:229-234.

21. Goyal R, Faizy AF, Siddiqui SS, Singhai M: Evaluation of TNF-a and IL-6 Levels in Obese and Non-obese Diabetics: Pre- and Postinsulin Effects. N Am J Med Sci 2012, 4:180-184.

22. Gómez-Hernández A, Escribano Ó, Perdomo L, Otero YF, García-Gómez G, Fernández S, Beneit N, Benito M: Implication of insulin receptor A isoform and IRA/IGF-IR hybrid receptors in the aortic vascular smooth muscle cell proliferation: role of TNF-a and IGF-II. Endocrinology 2013, 154:2352-2364.

23. Gómez-Hernández A, Otero YF, de las Heras N, Escribano O, Cachofeiro V, Lahera V, Benito M: Brown fat lipoatrophy and increased visceral adiposity through a concerted adipocytokines overexpression induces vascular insulin resistance and dysfunction. Endocrinology 2012, 153:1242-1255.

24. Kilkenny C, Browne WJ, Cuthill IC, Emerson M, Altman DG: Improving bioscience research reporting: the ARRIVE guidelines for reporting animal research. PLOS Biol 2010, 8:e1000412.

25. Escribano O, Guillén C, Nevado C, Gómez-Hernández A, Kahn CR, Benito M Beta-Cell hyperplasia induced by hepatic insulin resistance: role of a liver-pancreas endocrine axis through insulin receptor $A$ isoform. Diabetes 2009, 58:820-828.

26. Yonezawa T, Sanosaka M, Haga S, Kobayashi Y, Katoh K, Obara Y: Regulation of uncoupling protein 2 expression by long-chain fatty acids and hormones in bovine mammary epithelial cells. Biochem Biophys Res Commun 2008, 375:280-285.

27. Guerra C, Navarro P, Valverde AM, Arribas M, Brüning J, Kozak LP, Kahn CR, Benito M: Brown adipose tissue-specific insulin receptor knockout shows diabetic phenotype without insulin resistance. J Clin Invest 2001, 108:1205-1213.

28. Ross R: The pathogenesis of atherosclerosis-an update. N Engl J Med 1986, 314:488-500

29. Chisolm GM, Steinberg D: The oxidative modification hypothesis of atherogenesis: an overview. Free Radic Biol Med 2000, 28:1815-1826.

30. Mallat Z, Nakamura T, Ohan J, Lesèche G, Tedgui A, Maclouf J, Murphy RC: The relationship of hydroxyeicosatetraenoic acids and F2-isoprostanes to plaque instability in human carotid atherosclerosis. J Clin Invest 1999, 103:421-427.

31. Barry-Lane PA, Patterson C, van der Merwe M, Hu Z, Holland SM, Yeh ET, Runge MS: p47phox is required for atherosclerotic lesion progression in ApoE(-/-) mice. J Clin Invest 2001, 108:1513-1522

32. Mehrabian M, Allayee $H$, Wong J, Shi W, Wang XP, Shaposhnik Z, Funk CD, Lusis AJ: Identification of 5-lipoxygenase as a major gene contributing to atherosclerosis susceptibility in mice. Circ Res 2002, 91:120-126.

33. Kizaki T, Suzuki K, Hitomi Y, Taniguchi N, Saitoh D, Watanabe K, Onoé K, Day NK, Good RA, Ohno H: Uncoupling protein 2 plays an important role in nitric oxide production of lipopolysaccharide-stimulated macrophages. Proc Natl Acad Sci U S A 2002, 99:9392-9397.

34. Ryu JW, Hong KH, Maeng JH, Kim JB, Ko J, Park JY, Lee KU, Hong MK, Park SW, Kim YH, Han KH: Overexpression of uncoupling protein 2 in THP1 monocytes inhibits beta2 integrin-mediated firm adhesion and transendothelial migration. Arterioscler Thromb Vasc Biol 2004, 24:864-870.
35. Moukdar F, Robidoux J, Lyght O, Pi J, Daniel KW, Collins S: Reduced antioxidant capacity and diet-induced atherosclerosis in uncoupling protein-2-deficient mice. J Lipid Res 2009, 50:59-70.

36. Park JY, Park KG, Kim HJ, Kang HG, Ahn JD, Kim HS, Kim YM, Son SM, Kim IJ, Kim YK, Kim CD, Lee KU, Lee IK: The effects of the overexpression of recombinant uncoupling protein 2 on proliferation, migration and plasminogen activator inhibitor 1 expression in human vascular smooth muscle cells. Diabetologia 2005, 48:1022-1028.

37. Valverde AM, Arribas M, Mur C, Navarro P, Pons S, Cassard-Doulcier AM, Kahn CR, Benito M: Insulin-induced up-regulated uncoupling protein-1 expression is mediated by insulin receptor substrate 1 through the phosphatidylinositol 3-kinase/Akt signaling pathway in fetal brown adipocytes. J Biol Chem 2003, 278:10221-10231.

38. Teruel T, Valverde AM, Navarro P, Benito M, Lorenzo M: Inhibition of PI 3-kinase and RAS blocks IGF-I and insulin-induced uncoupling protein 1 gene expression in brown adipocytes. J Cell Physiol 1998, 176:99-109.

39. Wu H, Jiang C, Gan D, Liao Y, Ren H, Sun Z, Zhang M, Xu G: Different effects of low- and high-dose insulin on ROS production and VEGF expression in bovine retinal microvascular endothelial cells in the presence of high glucose. Graefes Arch Clin Exp Ophthalmol 2011, 249:1303-1310.

40. Pedersen SB, Lund S, Buhl ES, Richelsen B: Insulin and contraction directly stimulate UCP2 and UCP3 mRNA expression in rat skeletal muscle in vitro. Biochem Biophys Res Commun 2001, 283:19-25.

41. Langouche L, Vanhorebeek I, Vlasselaers D, Vander Perre S, Wouters PJ, Skogstrand K, Hansen TK, Van den Berghe G: Intensive insulin therapy protects the endothelium of critically ill patients. J Clin Invest 2005, 115:2277-2286.

42. Merial C, Bouloumie A, Trocheris V, Lafontan M, Galitzky J: Nitric oxide-dependent downregulation of adipocyte UCP-2 expression by tumor necrosis factor-alpha. Am J Physiol Cell Physiol 2000, 279:C1100-C1106.

43. Li LX, Yoshikawa H, Egeberg KW, Grill V: Interleukin-1 beta swiftly down-regulates UCP-2 mRNA in beta-cells by mechanisms not directly coupled to toxicity. Cytokine 2003, 23:101-107.

44. Li L, Yang G, Shi S, Yang M, Liu H, Boden G: The adipose triglyceride lipase, adiponectin and visfatin are downregulated by tumor necrosis factor-alpha (TNF-alpha) in vivo. Cytokine 2009, 45:12-19.

45. Zhou M, Xu A, Tam PK, Lam KS, Huang B, Liang Y, Lee IK, Wu D, Wang Y: Upregulation of UCP2 by adiponectin: the involvement of mitochondrial superoxide and hnRNP K. PLOS One 2012, 7:e32349.

46. Bai Y, Onuma H, Bai X, Medvedev AV, Misukonis M, Weinberg JB, Cao W, Robidoux J, Floering LM, Daniel KW, Collins S: Persistent nuclear factor-kappa B activation in Ucp2-/-mice leads to enhanced nitric oxide and inflammatory cytokine production. J Neurochem 2004, 89:1283-1292.

47. Emre Y, Hurtaud C, Nübel T, Criscuolo F, Ricquier D, Cassard-Doulcier AM: Mitochondria contribute to LPS-induced MAPK activation via uncoupling protein UCP2 in macrophages. Biochem J 2007, 402:271-278.

doi:10.1186/s12933-014-0108-9

Cite this article as: Gómez-Hernández et al: Antagonistic effect of TNF-alpha and insulin on uncoupling protein 2 (UCP-2) expression and vascular damage. Cardiovascular Diabetology 2014 13:108.

\section{Submit your next manuscript to BioMed Central and take full advantage of:}

- Convenient online submission

- Thorough peer review

- No space constraints or color figure charges

- Immediate publication on acceptance

- Inclusion in PubMed, CAS, Scopus and Google Scholar

- Research which is freely available for redistribution 